\title{
Younger Adolescents' Perceptions of Physical Activity, Exergaming, and Virtual Reality: Qualitative Intervention Development Study
}

Nuša Faric ${ }^{1}$, BSc, MSc; Eleanor Yorke ${ }^{1}$, BSc, MSc; Laura Varnes ${ }^{1}$, BSc, MSc; Katie Newby ${ }^{2}$, BSc, MSc, PhD; Henry WW Potts ${ }^{3}$, BA, MSc, PhD; Lee Smith ${ }^{4}$, BSc, MSc, PhD; Adrian Hon ${ }^{5}$, BA, MA; Andrew Steptoe ${ }^{1}$, BA, MA, DPhil, DSC; Abigail Fisher ${ }^{1}$, BSc, PhD

\footnotetext{
${ }^{1}$ Department of Behavioural Science \& Health, University College London, London, United Kingdom

${ }^{2}$ Faculty Research Centre for Advances in Behavioural Science, Coventry University, Coventry, United Kingdom

${ }^{3}$ Institute of Health Informatics, University College London, London, United Kingdom

${ }^{4}$ Cambridge Centre for Sport and Exercise Sciences, Anglia Ruskin University, Cambridge, United Kingdom

${ }^{5}$ Six to Start, London, United Kingdom
}

\section{Corresponding Author:}

Nuša Faric, BSc, MSc

Department of Behavioural Science \& Health

University College London

1-19 Torrington Place

London, WC1E $7 \mathrm{HB}$

United Kingdom

Phone: 4402067694466 ext 41914

Email: nfaric@gmail.com

\section{Related Article:}

This is a corrected version. See correction statement in: https://games.jmir.org/2019/3/e15657/

\section{Abstract}

Background: Novel strategies to promote physical activity (PA) in adolescence are required. The vEngage study aims to test whether a virtual reality (VR) exergaming intervention can engage younger adolescents (aged 13 to 15 years) with PA.

Objective: This study aimed to gather adolescents' views of using VR to encourage PA and identify the key features they would like to see in a VR exergaming intervention via interviews.

Methods: Participants were recruited through 2 schools in London, United Kingdom. Semistructured interviews were conducted with adolescents about their views on PA and what might work to increase PA, technology, knowledge and experience of VR, and desired features in a VR exergaming intervention. Data were analyzed using Framework Analysis.

Results: A total of 31 participants aged between 13 and 15 years (58\% female, $62 \%$ from nonwhite ethnicities) participated in this interview study. The vast majority had no awareness of government PA recommendations but felt they should be more thoroughly informed. All participants were positive about the use of VR in PA promotion. Rewards, increasing challenges, and a social or multiplayer aspect were identified by participants as crucial aspects to include in a VR exercise game. Barriers were related to cost of high-end systems. Being able to exercise at home was very appealing. VR exergaming was viewed as a way to overcome multiple perceived social and cultural barriers to PA, particularly for girls.

Conclusions: Key elements that should be incorporated into a VR game for health intervention were identified and described. These also included the use of rewards, novelty and enjoyment in immersive game play, multiplayer options, and real-world elements, as well as continual updates and new challenge levels. The use of VR to promote PA in adolescents is promising, but some barriers were raised.

(JMIR Serious Games 2019;7(2):e11960) doi: 10.2196/11960

\section{KEYWORDS}

exercise; obesity; video games; adolescent; adolescence; sports; health; leisure activities; virtual reality 


\section{Introduction}

\section{Limited Effectiveness of Physical Activity Interventions in Adolescents}

The health benefits of performing sufficient physical activity (PA) are well established and include reduced risk of noncommunicable diseases, reduced risk of premature mortality, and better mental health [1-3]. There is a dose-response relationship between PA and health with a $20 \%$ to $30 \%$ reduction in chronic illness and premature death for those that meet PA guidelines [1-3]. Adolescence (13 to 17 years) is a key time to intervene, as long-term PA likely confers maximum protective benefit [3]. Those who have high levels of PA in adolescence are more likely to be active in adulthood and lead healthier lifestyles $[4,5]$. There are psychological and social benefits of increased PA participation in adolescence [6]. However, less than $15 \%$ of boys and $10 \%$ of girls are achieving the UK government recommendation for adolescents of at least 60 min of moderate-to-vigorous physical activity (MVPA) per day [7]. Levels of adolescent PA are similarly low in other developed countries [8]. Without intervention, activity levels decline by around $7 \%$ per year throughout adolescence, particularly in girls [9]. Strategies to increase PA in this group are urgently required.

It remains unclear what works best to change adolescent PA behavior [10,11]. A recent review of digital PA interventions for adolescents recommended that education, goal setting and feedback, self-monitoring, and parental support should be incorporated [12].

Despite recommendation that conducting formative work with target users is important to intervention development $[13,14]$, very few PA interventions have involved adolescents in development. Before developing a school-based intervention, Corder et al conducted focus groups with participants aged between 16 and 18 years and identified choice, novelty, mentorship, rewards, competition, and flexibility as key aspects that young people would like to be included [15]. Although co-design or participatory design (PD) of digital health interventions is not necessarily recommended (as no higher effectiveness was found for games developed with PD), user input is beneficial [16]. This is particularly applicable when considering digital PA interventions [16].

\section{Digital Physical Activity Interventions in Adolescents}

Digital interventions are likely to be particularly appealing for adolescents; more than $90 \%$ play video games for at least an hour per day [17]. A variety of exergames are available and many have been commercial successes: Wii Fit sold over 22 million copies worldwide in its first 4 years [18]. More recently, an augmented reality exergame run on smartphones, Pokémon Go, has seen over 800 million downloads [19]. A study conducted in Hong Kong (participants N=210; aged 16 to 64 years) found that the use of Pokémon Go was associated with a short-term increase in the players' daily walking and running distances, particularly in those who were less physically active [20].
Levels of PA and physiological response when exergaming are comparable with field-based PA, and significantly increased when compared with standard gaming [21]. Exergames also enhanced enjoyment, self-efficacy, and motivation for PA [21]. Exergaming interventions can lead to weight loss in overweight adolescents [22,23]. However, past research has generally involved small studies and earlier generation exergames.

Virtual reality (VR) has the potential to enhance the exergaming experience through immersion and presence contributing to the feeling of absorption, flow, and fun [23,24]. New generation VR technologies deliver increasingly realistic experiences at decreasing cost. Some small laboratory-based studies in adults have found that immersive VR exergames resulted in the same or higher intensity of exercise as standard exercise conditions, but with higher ratings of enjoyment and interest [25,26]. One study also found that perceived exertion was lower and self-efficacy was higher during VR cycling compared with standard stationary cycling [27]. An exploratory pre-post study including 9 children and adolescents suggested that an immersive VR game enhanced motivation to be active [28]. Immersion is likely to distract participants from exertion and possibly negative thinking during PA.

We hypothesized that a VR exergaming intervention could increase PA in adolescents. The aim of this study was to interview adolescents about their recommendations for a PA intervention, use of technology, gaming, and interest in VR for PA.

\section{Methods}

\section{Participants}

Participants were recruited from 2 secondary schools in London, United Kingdom between January and July 2017. To be eligible, participants had to be aged between 13 and 17 years. Given the need to recruit a high number of girls, one was a girl's school whereas the other was mixed. Both schools were in areas of high ethnic and socioeconomic diversity. Each school sent information packs home with students from 2 classes. In total, approximately 65 packs were sent to the interested students. Interested students each returned and completed the parental consent and child assent form. We aimed to interview approximately 30 young people based on guidance provided by Fugard and Potts [29] and we interviewed all students who returned the completed consent forms.

\section{Ethics}

Ethical approval was provided by the University College London Ethics committee (Project ID 10213/001) with all participants and their parents/caregivers providing informed written consent.

\section{Qualitative Interviews}

We used a semistructured interview. We asked the following: "What is the amount of time you spend being active as well as inactive per week in hours?"; "What is your average sitting time per day?"; "Do you know about the recommended guidelines for PA in your age group?"; What might encourage people of your age to become more physically active?"; "What is your current technology use- what do you use and how long per day 
or week?"; "What interest you about a particular game?"; "Do you know much about VR?"; "What are your experiences and/or opinion on using VR?"; "Do you use any other health-related technology?"; and "How would you help increase PA through use of technology and VR?". Finally, participants were asked about key features desired in a VR exergame. Interviews were conducted face-to-face in schools between June and July 2017 by 2 researchers (EY and LV) and transcribed verbatim.

\section{Analysis}

Framework Analysis was used, which is a flexible and systematic approach for analysis of semistructured interviews [30]. A total of 2 researchers (EY and LV) independently analyzed 3 transcripts, each developing an initial set of codes. The participant's responses within the interviews were assigned codes and coded into a framework matrix, along with relevant quotes to make it visually straightforward and easy to track. Then 2 additional researchers (NF and AF) independently interpreted the data to identify common themes among responses. Theme prevalence was not determined quantitatively but instead grouped together into main themes described below. All researchers then met and discussed their interpretations and codes, compared them, and made minor adjustments to create the final framework. The final interpretations are shared below, with illustrative quotes (followed by participant's gender and age).

\section{Results}

\section{Overview}

A total of 31 participants aged between 13 and 15 years were interviewed. Of them, 58\% (18/31) were girls. Participants identified their ethnicity as white British $(n=7)$, white other $(n=5)$, multiple ethnicities $(n=5)$, Asian $(n=5)$, Indian $(n=2)$, Bangladeshi $(\mathrm{n}=2)$, Pakistani $(\mathrm{n}=1)$, Caribbean $(\mathrm{n}=1)$, African $(\mathrm{n}=1)$, and black $(\mathrm{n}=2)$. Interviews lasted for 40 to 70 min (mean $55 \mathrm{~min}$ ). The themes were apparent and straightforward with no disagreements between the researchers. The main themes and their subthemes are described in Table 1.

Table 1. Identified main themes and subthemes.

\begin{tabular}{ll}
\hline Main theme & Subthemes \\
\hline PA $^{\mathrm{a}}$ and sedentary time & $\begin{array}{l}\text { Adolescents were not aware of the PA guidelines for people of their age or of all health benefits associated with PA or } \\
\text { consequences of not performing sufficient PA }\end{array}$ \\
General technology use & $\begin{array}{l}\text { Smartphones were the technology most used by adolescents for recreation; Gaming was popular and exergames were } \\
\text { a positive past experience, but some games were no longer played (eg, Just Dance or Pokémon Go) }\end{array}$ \\
Exergaming & $\begin{array}{l}\text { Exergames were seen as a fun, motivating, and encouraging movement covertly; There was a strong appeal of exercising } \\
\text { at home and overcoming cultural or social barriers, particularly for girls; Exergames were not seen as a replacement if } \\
\text { already involved in sport }\end{array}$ \\
& $\begin{array}{l}\text { Positivity toward VR but limited experience; Whole body movement, presence, and novelty appealing in VR; Barriers } \\
\text { with VR included bulky headsets, addiction, and price; Perceived parental concern about using VR for PA; Simple } \\
\text { public health messages about screen time preferred }\end{array}$
\end{tabular}

${ }^{\mathrm{a}} \mathrm{PA}$ : physical activity.

${ }^{\mathrm{b}}$ VR: virtual reality.

\section{Physical Activity and Sedentary Time}

\section{Adolescents Were Not Aware of the Recommended Guidelines for Physical Activity and of All Health Benefits and Risks Associated With Physical Activity}

Awareness of PA recommendations for adolescents was very low with 94\% (29/31) participants guessing the recommended guidelines. The intensity or resistance exercises were not mentioned. Participants felt strongly that people of their age should be informed of PA recommendations and the links between PA and health. Girls in particular reported this knowledge as a key motivation for being active and felt this would increase activity in their peers:

Give [young people] some of the risks that could happen in the future if you do not keep fit and not healthy. [F, 14]

When probed about how they might like this information delivered, the consensus was visually:

Maybe videos on how to do it because I don't think people [my age] really take in facts. [F, 14]
But tangible rewards were also important motivators for PA:

So there's something to work for instead of just saying
do it and you'll be more active. You have to give them
something at the end. Anything people my age will
find fun. Probably mostly money. [M, 15]

\section{General Technology Use}

\section{Mainly Smartphones, Mainly for Recreation}

All participants used technology up to 6 hours per day (eg, smartphone and computer), mainly for recreational uses (eg, gaming and social media) but also practical (eg, homework). Boys used technology mainly for gaming, whereas girls used technology for watching videos, listening to music, and socializing (reported logging into social media between 30 and 55 times per day). There were positive and negative perceptions of technology related to PA:

I saw this report, kids nowadays are more overweight compared to before, and that's probably because we're always just sitting down on our phones, tablets and stuff. [F, 14] 
[use technology to encourage people to go outside] because obviously with technology people don't go outside as much as they used to. So, I don't know, you just need to get people out. Because the phone is so interesting. [F, 15]

\section{Gaming was Popular and Exergames Were a Positive Past Experience}

The majority of participants engaged in some type of gaming. Games played were diverse, but common features were continual challenges/levels of difficulty, rewards, competition, social aspects, and story modes. A total of 5 participants specifically mentioned games that were simple, slow to build, and ongoing as leading to playing for a number of years. Exergames were often mentioned; all participants had played them, and they were generally described positively, but always in the past tense such as Just Dance (Nintendo Wii):

I really liked that [Just Dance] but I don't know, it just died out for some reason, I don't know why. We had the dancing thing, to step on it, all that kind of stuff, yes. Yes, that was sick. [F, 15]

\section{Pokémon, Gone}

Many participants described Pokémon Go (released in July 2016) as something they had tried but no longer used, with some stating technical reasons as off-putting:

It was really fun in the beginning, but then the servers were overwhelmed with too many people playing. [M, 14]

[I played it] only once then found out it used up most of my data. [F, 13]

Many mentioned safety concerns preventing use (Web-based security, road safety, and getting lost), often reflecting on negative stories they had heard in the media. Others felt it had increased their PA, but still referred to it is as a previous experience:

Well, at the time where it was big it was really cool because it actually made me go outside and look around and stuff. It did made me walk a lot more. [F, 14]

\section{Exergames: Fun, Motivating, and Encouraging Movement Covertly}

Exergames were viewed as appealing because they were fun, motivating, and good ways to encourage incidental PA:

I think it's good because some people may think that,

"I don't want to do this sport," but actually, they are, without realising. [F, 15]

It's way better because you're working out but you're having fun and you don't realise you're working out. [F, 14]

Social benefits and competition when exergaming were also described as appealing:

It's nice because other people can actually watch it at the same time, it's not just one person involved in it. So, it makes it fun and motivates the person to even try harder, so it creates competition as well. [F, 15]

\section{Strong Appeal of Exercising at Home and Overcoming Cultural or Social Barriers}

Participants particularly liked the idea that exergames allowed activity in the home:

Getting fit isn't always enjoyable and it could also make you confident to do it [...] You can do it in the privacy of your own home. [F, 14]

Virtual reality...in your own home because people like going running but sometimes people can't...my parents don't always let me out, so doing it in my own home...Yes. And also for Muslims, you have to cover your body, so it's hard to go running while covering your body, whereas at home it's very easy. [F, 14]

\section{Exergames Not a Replacement if Already Involved in Sport}

However, those who were already involved in sport tended to think exergames should not be a replacement:

I think they're useful, but I think it's better for people to actually do sport. [F, 14]

\section{Experience of Virtual Reality}

\section{Positivity Toward Virtual Reality but Limited Experience}

Nearly all participants were extremely positive about the idea of using or trying VR. More than half had tried some kind of VR (usually smartphone-based headsets). There were no apparent gender differences in wanting to try, having tried, or liking VR. A total of 6 participants described having tried a one-off fully immersive experience in an external venue, and 1 had high-end equipment at home. Very few had any kind of VR equipment at home, and if they did, it was usually referred to as being owned by a parent or older sibling. Participants wanted to own it but felt the price was prohibitive:

I've used it once when I went to a big shopping centre. I thought it was quite cool but then I looked at the price: thousands. [M, 15]

\section{Whole Body Movement, Presence, and Novelty Appealing in Virtual Reality}

Those who had tried VR were positive about it, describing it frequently as cool, exciting, fun, and highlighting the whole body movement, presence, and novelty as appealing. Only 1 participant thought it was pointless (F, 14).

You're actually in the game, you can feel you're moving with it, it's not just your fingers and your eyes, it's your whole body is involved so it's more involved. $[\mathrm{F}, 15]$

I think it's absolutely cool. For [named a standard games console], you sit in front of a TV, but now when it actually feels like you're there, it makes it way more interesting and fun. [F, 15] 
Other benefits were raised such as widening understanding/experience or creating safe spaces to try new activities:

It is like being in real life, but safer, if you know what I mean. Like if you do something serious, it is not real. So, in a way, it is safer to learn things. [F, 14]

\section{Barriers With Virtual Reality Included Bulky Headsets, Addiction, and Price}

There were technical barriers including the size and weight of the headset. Barriers were usually countered with belief that these issues would be addressed as the technology advanced:

I think it's a great concept, but I think it has a way to go. It's not really developed as much yet...Because right now you have to wear like a massive headset that's really heavy and you have to move around and it's not as receptive of the little controls. [M, 15, owned VR headset]

As with other types of gaming, a prominent concern was fear of addiction:

Just as they're addicted to PlayStation and all of that, they would be addicted to this game. [F, 14]

Some participants described physical symptoms of use, such as nausea, dizziness, headaches, and fear of bumping into others. However, nearly all believed that VR was going to be extremely popular in the future:

I think virtual reality is the future of technology and it will be more involved in everyday life. [F, 14]

\section{Perceived Parental Concern About Using Virtual Reality for Physical Activity}

Although participants felt positively about a VR exergaming intervention, there was a perception that parents might not be supportive:
Some parents would be really opposing to it. Just because I know some of my friends, their parents don't like them being on electronics at all. [F, 14]

Parents wouldn't buy that for their children because obviously price. [M, 13]

\section{Simple Messages About Screen Time Preferred}

When asked about how to counteract potentially conflicting public health messages around reducing screen time versus introducing an exergaming intervention, the consensus among participants was that providing information would be sufficient. Many said things like just tell us (that screen time needs to be limited; M, 15) or suggested that it was sitting rather than screen time that was the issue:

I would say if it's in front of a screen and it does encourage physical activity, it doesn't really matter that it's in front of a screen, as long as you're engaging. [M, 14]

In addition, this approach could appeal to gamers, who were perceived to be sedentary:

They're [gamers] probably more interested in video games, so the virtual reality might encourage them more [to be physically active]. [F, 14]

This view was supported by participants who identified as gamers:

Because it's a game. Immediately I hear game, personally, I'm into it already and think it will be more exciting. [M, 13]

Additional features that participants reported they would like to see in a VR exergame are shown in Table 2 with supporting quotes. 
Table 2. Desired features of virtual reality physical activity intervention.

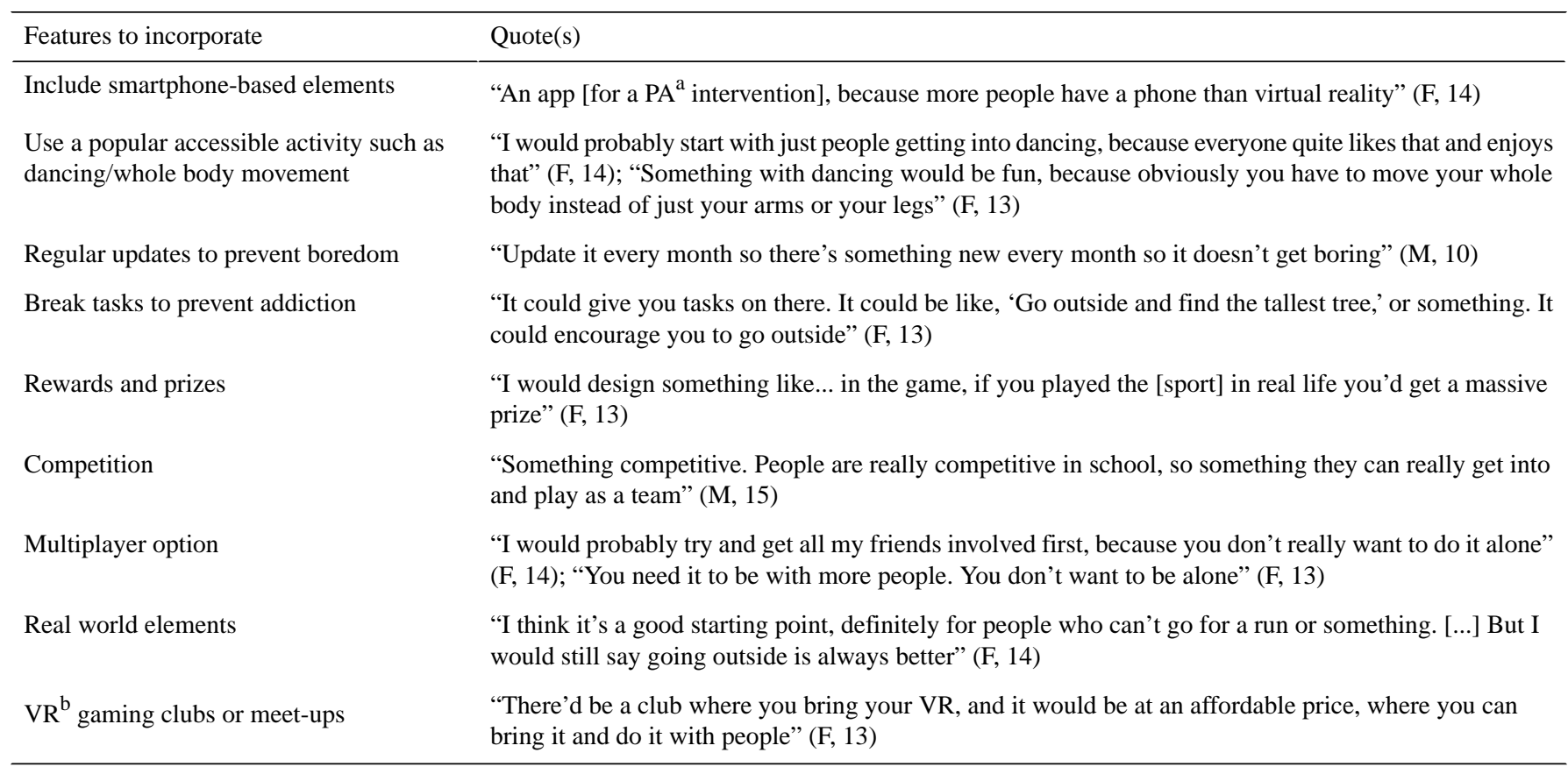

${ }^{\mathrm{a}} \mathrm{PA}$ : physical activity.

${ }^{b}$ VR: virtual reality.

\section{Discussion}

\section{Principal Findings}

Our findings suggest strong support for the potential of VR to promote PA in adolescents. However, there were a number of factors relevant to researchers developing any digital PA intervention discussed below.

Participants raised the importance of parental support, in line with previous research on digital health interventions for adolescents and studies exploring determinants of adolescent PA [12]. We are separately interviewing parents and teachers about their perceptions of VR exergaming and PA.

Awareness of any government guidelines around PA was low but desire for knowledge was high. Our participants (particularly girls) felt that an educational component would be desirable, and presenting information about benefits of PA in a visual format was recommended. This is in line with our previous work suggesting less than $20 \%$ of parents knew the government PA guidelines for their children [31]. A review of 17 adolescent PA trials found that education alone did not result in behavior change. However, multicomponent studies incorporating education found strong effects on PA [10]. Multicomponent studies can be labor intensive (eg, requiring alteration of environmental infrastructure), so their potential for wide-scale implementation is questionable. The present digital revolution and the ubiquity and frequency of technology use by adolescents, highlighted in our study, has greatly increased potential reach.

Rewards were suggested as being important to encourage PA engagement (particularly in boys, but also for some girls), in line with previous studies [15,32]. The rewards suggested were always material (usually financial). Financial rewards are effective in motivating PA in adults [33], and a trial using incentives and gamification to promote PA in families had positive effects [34]. In line with theories such as the self-determination theory, fun and enjoyment are intrinsically motivating and key motivators for gaming [35], and most adolescents engage in gaming without a material reward. Fun was consistently reported as a reason for engaging in exergaming by our participants.

\section{Appeal of Home-Based Physical Activity}

Our data suggest that a home-based PA digital intervention is appealing to our target population. Most previous interventions targeting adolescent PA have been at least partially delivered in schools, but a more recent cohort found $70 \%$ to $81 \%$ boys and girls said they would choose to be active at home or in a gym/leisure center, as opposed to in school or outdoors [32]. Particularly for the girls in our study, home-based PA had the potential to overcome cultural and social barriers. In addition, they were viewed as appealing because they harnessed behaviors (such as gaming) that were already being performed. Many suggested including additional intervention elements such as community-based meet ups or groups to enhance the social elements and foster competition. In the aforementioned quantitative survey, adolescents also reported they would choose to be active with their friends (over, eg, family) [32]. However, some girls in our study felt the ability to exercise privately in their own home was appealing, so an optional social element would be best.

\section{Potential for Virtual Reality Interventions}

At the time of writing this paper, the cost of the high-end VR equipment required to create a fully immersive exergaming experience was prohibitive (around $£ 2000$ for the equipment and necessary computer), and this was recognized as a barrier 
by our participants. However, participants expect costs to fall. This is likely and ownership will increase [36]. We are aware that the novelty, reported as important in our study and others [15], will therefore also diminish. This strengthens the argument for developing a digital intervention within a theory-based framework, so the active ingredients can be replicated using other platforms in future. This also emphasizes the importance of making digital interventions intrinsically fun and enjoyable so that they are not reliant only on novelty. Indeed, in our study the participants who were most positive were those who had tried VR.

Our study had specific and narrow aims and around $60 \mathrm{~min}$ worth of discussion per participant. Interviews were conducted by researchers experienced in working with adolescents. Therefore, we believed our sample size held sufficient information power to address the research questions [37].

Our participants desired continual updates and additional challenge levels, and these are key elements of gaming that can map to specific behavior change techniques in a digital health intervention [38]. Embedding the digital platform at the center of a multicomponent intervention, and working with professional developers who understand how to keep a game engaging and challenging, is therefore crucial for success.

\section{Limitations}

The results were obtained from a reasonable number of participants in comparison with other studies using thematic analysis [29], with a diverse range of ethnicities and more girls than boys. It is possible that those who were more interested in health agreed to participate. However, as less than $10 \%$ to $15 \%$ of the UK adolescent population meet PA recommendations [7], it is very unlikely that we only recruited active participants. The focus on technology as well as PA was also likely to attract a mix of interests. All participants were aged between 13 and 15 years, and results may have been different if opinions were from older adolescents. It is likely that our intervention will target younger adolescents given the value in intervening early (VR gaming is not recommended in those younger than 13 years). We will also continue to work with our public engagement groups and adolescent steering committee to gather information from adolescents from diverse backgrounds.

\section{Conclusions}

The results of this study suggest that an intervention to promote PA in adolescents that has VR exergaming at the core is promising. However, it is likely that additional elements will be required to produce sustained behavior change including educational elements, tangible rewards, prompts to encourage breaks, and parental support.

\section{Acknowledgments}

The vEngage study was funded by the Medical Research Council (Grant number MR/R015430/1). The authors are extremely grateful to all participating schools and young people and their families for their support. The authors would also like to thank their adolescent steering committee who have helped shape the original idea for the study.

\section{Conflicts of Interest}

This research is sponsored by the Medical Research Council industry partnership grant and leads to development of a VR game licensed by Six to Start. There is no legal, financial, or commercial conflict with our industry partner company, Six to Start.

\section{References}

1. Warburton DE, Nicol CW, Bredin SS. Health benefits of physical activity: the evidence. CMAJ 2006 Mar 14;174(6):801-809 [FREE Full text] [doi: 10.1503/cmaj.051351] [Medline: 16534088]

2. Arem H, Moore SC, Patel A, Hartge P, Berrington DG, Visvanathan K, et al. Leisure time physical activity and mortality: a detailed pooled analysis of the dose-response relationship. JAMA Intern Med 2015 Jun;175(6):959-967 [FREE Full text] [doi: 10.1001/jamainternmed.2015.0533] [Medline: 25844730]

3. Reiner M, Niermann C, Jekauc D, Woll A. Long-term health benefits of physical activity--a systematic review of longitudinal studies. BMC Public Health 2013;13:813 [FREE Full text] [doi: 10.1186/1471-2458-13-813] [Medline: 24010994]

4. Telama R, Yang X, Viikari J, Välimäki I, Wanne O, Raitakari O. Physical activity from childhood to adulthood: a 21-year tracking study. Am J Prev Med 2005 Apr;28(3):267-273. [doi: 10.1016/j.amepre.2004.12.003] [Medline: 15766614]

5. Hallal PC, Victora CG, Azevedo MR, Wells JC. Adolescent physical activity and health: a systematic review. Sports Med 2006;36(12):1019-1030. [Medline: 17123326]

6. Eime RM, Young JA, Harvey JT, Charity MJ, Payne WR. A systematic review of the psychological and social benefits of participation in sport for children and adolescents: informing development of a conceptual model of health through sport. Int J Behav Nutr Phys Act 2013 Aug 15;10:98 [FREE Full text] [doi: 10.1186/1479-5868-10-98] [Medline: 23945179]

7. Health Survey for England. National Centre for Social Research, UCL, London: NHS Digital; 2017 Dec 13. Health survey for England 2016: Children's health URL: http://healthsurvey.hscic.gov.uk/media/63769/HSE2016-Child-health.pdf [accessed 2018-12-12] [WebCite Cache ID 75zDZ3bMZ]

8. Kalman M, Inchley J, Sigmundova D, Iannotti RJ, Tynjälä JA, Hamrik Z, et al. Secular trends in moderate-to-vigorous physical activity in 32 countries from 2002 to 2010: a cross-national perspective. Eur J Public Health 2015 Apr;25 Suppl 2:37-40. [doi: 10.1093/eurpub/ckv024] [Medline: 25805785] 
9. Corder K, Sharp SJ, Atkin AJ, Griffin SJ, Jones AP, Ekelund U, et al. Change in objectively measured physical activity during the transition to adolescence. Br J Sports Med 2014 Apr 9;49(11):730-736 [FREE Full text] [doi: 10.1136/bjsports-2013-093190] [Medline: 24273308]

10. van Sluijs EM, McMinn AM, Griffin SJ. Effectiveness of interventions to promote physical activity in children and adolescents: systematic review of controlled trials. Br Med J 2007 Oct;335(7622):703 [FREE Full text] [doi: 10.1136/bmj.39320.843947.BE] [Medline: 17884863]

11. Metcalf B, Henley W, Wilkin T. Effectiveness of intervention on physical activity of children: systematic review and meta-analysis of controlled trials with objectively measured outcomes (EarlyBird 54). Br Med J 2012 Sep 27;345:e5888. [doi: 10.1136/bmj.e5888] [Medline: 23044984]

12. Rose T, Barker M, Maria JC, Morrison L, Lawrence W, Strömmer S, et al. A systematic review of digital interventions for improving the diet and physical activity behaviors of adolescents. J Adolesc Health 2017 Dec;61(6):669-677 [FREE Full text] [doi: 10.1016/j.jadohealth.2017.05.024] [Medline: 28822682]

13. Craig P, Dieppe P, Macintyre S, Michie S, Nazareth I, Petticrew M, Medical Research Council Guidance. Developing and evaluating complex interventions: the new Medical Research Council guidance. Br Med J 2008 Sep 29;337:a1655 [FREE Full text] [doi: 10.1136/bmj.a1655] [Medline: 18824488 ]

14. Bartholomew LK, Parcel GS, Kok G. Intervention mapping: a process for developing theory- and evidence-based health education programs. Health Educ Behav 1998 Oct;25(5):545-563. [Medline: 9768376]

15. Corder K, Schiff A, Kesten JM, van Slujis EM. Development of a universal approach to increase physical activity among adolescents: the GoActive intervention. BMJ Open 2015 Aug 25;5(8):e008610 [FREE Full text] [doi: 10.1136/bmjopen-2015-008610] [Medline: 26307618]

16. DeSmet A, Thompson D, Baranowski T, Palmeira A, Verloigne M, de Bourdeaudhuij I. Is participatory design associated with the effectiveness of serious digital games for healthy lifestyle promotion? A meta-analysis. J Med Internet Res 2016 Apr 29;18(4):e94 [FREE Full text] [doi: 10.2196/jmir.4444] [Medline: 27129447]

17. Granic I, Lobel A, Engels RC. The benefits of playing video games. Am Psychol 2014 Jan;69(1):66-78. [doi: 10.1037/a0034857] [Medline: 24295515]

18. Nintendo.: Nintendo; 2019 Mar. Top Selling Item Units URL: https://www.nintendo.co.jp/ir/en/finance/software/wii.html [accessed 2019-01-17] [WebCite Cache ID 75zDL1W26]

19. Pocketgamer. Pokemon go captures 800 million downloads URL: https://www.pocketgamer.biz/news/68209/ pokemon-go-captures-800-million-downloads/ [accessed 2019-02-06] [WebCite Cache ID 75zDjW1zW]

20. Ma BD, Ng SL, Schwanen T, Zacharias J, Zhou M, Kawachi I, et al. Pokémon GO and physical activity in Asia: multilevel study. J Med Internet Res 2018 Dec 15;20(6):e217 [FREE Full text] [doi: 10.2196/jmir.9670] [Medline: 29907559]

21. Gao Z, Chen S, Pasco D, Pope Z. A meta-analysis of active video games on health outcomes among children and adolescents. Obes Rev 2015 Sep;16(9):783-794. [doi: 10.1111/obr.12287] [Medline: 25943852]

22. Staiano AE, Abraham AA, Calvert SL. Adolescent exergame play for weight loss and psychosocial improvement: a controlled physical activity intervention. Obesity (Silver Spring) 2013 Mar;21(3):598-601 [FREE Full text] [doi: 10.1002/oby.20282] [Medline: 23592669]

23. Staiano AE, Marker AM, Beyl RA, Hsia DS, Katzmarzyk PT, Newton RL. A randomized controlled trial of dance exergaming for exercise training in overweight and obese adolescent girls. Pediatr Obes 2017 Dec;12(2):120-128 [FREE Full text] [doi: 10.1111/ijpo.12117] [Medline: 26918815]

24. Csikszentmihalyi M. Beyond Boredom and Anxiety: Experiencing Flow in Work and Play. San Francisco: Jossey-Bass Publishers; 1975.

25. Slater M, Wilbur S. A framework for immersive virtual environments (FIVE): speculations on the role of presence in virtual environments. Presence (Camb) 1997 Dec;6(6):603-616. [doi: 10.1162/pres.1997.6.6.603]

26. Zeng N, Pope Z, Gao Z. Acute effect of virtual reality exercise bike games on college students' physiological and psychological outcomes. Cyberpsychol Behav Soc Netw 2017 Jul;20(7):453-457. [doi: 10.1089/cyber.2017.0042] [Medline: 28715263]

27. Murray EG, Neumann DL, Moffitt RL, Thomas PR. The effects of the presence of others during a rowing exercise in a virtual reality environment. Psychol Sport Exer 2016 Jan;22:328-336. [doi: 10.1016/j.psychsport.2015.09.007] [Medline: 30872122]

28. Finkelstein S, Suma EA. Astrojumper: Motivating exercise with an immersive virtual reality exergame. Presence (Camb) 2011 Feb;20(1):78-92. [doi: 10.1162/pres a 00036]

29. Fugard AJ, Potts HW. Supporting thinking on sample sizes for thematic analyses: a quantitative tool. Int J Soc Res Methodol 2015 Feb 10;18(6):669-684. [doi: 10.1080/13645579.2015.1005453]

30. Gale NK, Heath G, Cameron E, Rashid S, Redwood S. Using the framework method for the analysis of qualitative data in multi-disciplinary health research. BMC Med Res Methodol 2013;13:117 [FREE Full text] [doi: 10.1186/1471-2288-13-117] [Medline: 24047204]

31. Sawyer A, Smith L, Schrempft S, van Jaarsveld CH, Wardle J, Fisher A. Primary caregiver knowledge of paediatric physical activity recommendations in the United Kingdom and its association with caregiver behaviour: an observational study. BMC Public Health 2014 Aug 4;14:795 [FREE Full text] [doi: 10.1186/1471-2458-14-795] [Medline: 25092511] 
32. Corder K, Atkin AJ, Ekelund U, van Sluijs EM. What do adolescents want in order to become more active? BMC Public Health 2013 Aug 5;13:718 [FREE Full text] [doi: 10.1186/1471-2458-13-718] [Medline: 23914878]

33. Barte JC, Wendel-Vos GC. A systematic review of financial incentives for physical activity: The effects on physical activity and related outcomes. Behav Med 2017;43(2):79-90. [doi: 10.1080/08964289.2015.1074880] [Medline: 26431076]

34. Zimmerman FJ. Using behavioral economics to promote physical activity. Prev Med 2009 Oct;49(4):289-291. [doi: 10.1016/j.ypmed.2009.07.008] [Medline: 19632266]

35. Ryan RM, Rigby CS, Przybylski A. The motivational pull of video games: a self-determination theory approach. Motiv Emot 2006 Nov 29;30(4):344-360. [doi: 10.1007/s11031-006-9051-8]

36. Avila L, Bailey M. Virtual reality for the masses. IEEE Comput Grap Appl 2014 Sep;34(5):103-104. [doi: 10.1109/MCG.2014.103]

37. Malterud K, Siersma VD, Guassora AD. Sample size in qualitative interview studies: guided by information power. Qual Health Res 2015 Nov 27. [doi: 10.1177/1049732315617444] [Medline: 26613970]

38. Cugelman B. Gamification: what it is and why it matters to digital health behavior change developers. JMIR Serious Games 2013;1(1):e3 [FREE Full text] [doi: 10.2196/games.3139] [Medline: 25658754]

\title{
Abbreviations \\ PA: physical activity \\ PD: participatory design \\ VR: virtual reality
}

\author{
Edited by G Eysenbach; submitted 16.08.18; peer-reviewed by C Kracht, S Gallagher, T Guetterman; comments to author 08.10.18; \\ revised version received 12.01.19; accepted 17.02.19; published 17.06.19 \\ Please cite as: \\ Faric N, Yorke E, Varnes L, Newby K, Potts HWW, Smith L, Hon A, Steptoe A, Fisher A \\ Younger Adolescents' Perceptions of Physical Activity, Exergaming, and Virtual Reality: Qualitative Intervention Development Study \\ JMIR Serious Games 2019;7(2):e11960 \\ URL: http://games.jmir.org/2019/2/e11960/ \\ doi: $\underline{10.2196 / 11960}$ \\ PMID: $\underline{31210135}$
}

CNuša Faric, Eleanor Yorke, Laura Varnes, Katie Newby, Henry WW Potts, Lee Smith, Adrian Hon, Andrew Steptoe, Abigail Fisher. Originally published in JMIR Serious Games (http://games.jmir.org), 17.06.2019. This is an open-access article distributed under the terms of the Creative Commons Attribution License (https://creativecommons.org/licenses/by/4.0/), which permits unrestricted use, distribution, and reproduction in any medium, provided the original work, first published in JMIR Serious Games, is properly cited. The complete bibliographic information, a link to the original publication on http://games.jmir.org, as well as this copyright and license information must be included. 